\title{
Pengaruh E-Learning Sebagai \\ Media Pelatihan dan Pengembangan Terhadap Kinerja Karyawan BCA KCU Tangerang
}

\author{
Indah Permatasari $^{[1]}$ Hardiyan $^{[2]}$ \\ Program Studi Sistem Informasi, STMIK Nusa Mandiri ${ }^{[1]}$ \\ Program Studi Manajemen Informatika, AMIK BSI Tangerang ${ }^{[2]}$ \\ ips0101@gmail.com ${ }^{[1]}$, hardiyan.hry@bsi.ac.id ${ }^{[2]}$
}

\begin{abstract}
Abstrak-Pembelajaran merupakan strategi dan sekaligus sebagai solusi bagi suatu organisasi/perusahaan maupun individu untuk beradaptasi dan mengambil tindakan yang efektif untuk menciptakan keunggulan daya saing. Perusahaan perlu meningkatkan kinerja karyawannya agar berprestasi dan sukses dalam pencapaian tujuan strategis organisasi. PT Bank BCA menyadari bahwa pengembangan dan pelatihan adalah upaya untuk menciptakan SDM yang berkuaitas. Maka, e-learning adalah salah satu metode pembelajaran yang digunakan dalam pengembangan dan pelatihan. Penelitian ini bertujuan untuk mengetahui apakah peningkatan kinerja dalam proses pelatihan dan pengembangan dapat dilakukan melalui media e-learning di BCA menggunakan pendekatan kuantitatif dengan jenis penelitian deskriptif, karena berusaha menggambarkan mengenai fakta mengenai suatu kejadian dan situasi yang terjadi di BCA KCU Tangerang. Pengumpulan data dilakukan dengan metode survey dengan membagikan kuisioner kepada responden karyawan BCA KCU Tangerang. Hasil penelitian menunjukkan bahwa E-learning di BCA KCU Tangerang mempunyai pengaruh yang cukup baik dan berarah positif terhadap kinerja karyawan BCA KCU Tangerang dari hipotesis dimana data $r$ hitung>dari r table $(2,756>1,686)$.
\end{abstract}

Kata Kunci-e-learning, pelatihan dan pengembangan, kinerja

\section{PENDAHULUAN}

Pembelajaran merupakan strategi dan sekaligus sebagai solusi bagi suatu organisasi/perusahaan maupun individu untuk beradaptasi dan mengambil tindakan yang efektif untuk menciptakan keunggulan daya saing. Tujuan utama sistem manajemen pengetahuan adalah meningkatkan kompetensi pegawai di perusahaan sebagai bagian dari pengelolaan sumber daya manusia. Perkembangan teknologi informasi (TI) yang sedemikian pesat tersebut menciptakan kultur baru bagi semua orang di seluruh dunia. Integrasi teknologi informasi ke dalam dunia usaha telah menciptakan pengaruh besar. Dengan memanfaatkan kecanggihan teknologi informasi, sistem manajemen pengetahuan di perusahaan dapat digunakan secara efisien dan efektif serta berkelanjutan.

Salah satu produk integrasi teknologi informasi ke dalam dunia usaha adalah E-Learning atau elektronik learning. Saat ini E-Learning mulai mengambil perhatian banyak pihak, baik dari kalangan akademik, profesional, perusahaan maupun industri. E-Learning merupakan metode pembelajaran menggunakan media elektronik (audio/visual) melalui metode internet. Saat ini E-Learning muncul sebagai paradigma baru dalam bidang pendidikan modern dan sudah banyak penelitian memperlihatkan bukti empiris dalam mendukung gagasan memanfaatkan teknologi $E$ Learning secara efektif dapat memberikan banyak peluang [5].

Sistem E-Learning juga sudah diterapkan di perusahaan maju seperti PT. Bank Central Asia, TBK. sejak tahun 2009. Dimana BCA menerapkan sistem E-Learning sebagai salah satu penunjang pelatihan dan pengembangan Sumber Daya Manusia (Karyawan) BCA. Sumber daya manusia yang berkualitas merupakan aspek penting dalam mempertahankan keunggulan kompetitif dan mendukung strategi bisnis BCA. Bank senantiasa berupaya dalam meningkatkan kapabilitas dan kemampuan sumber daya manusia, baik melalui pelatihan profesional yang berkelanjutan maupun dengan merekrut staf berkualitas.

BCA terus memperbaharui dan mengembangkan program pelatihan agar para karyawan tetap menjadi yang terdepan dalam lingkungan bisnis yang dinamis. Program pelatihan dirancang untuk meningkatkan keterampilan dan pengetahuan staf dari semua divisi termasuk layanan penyelesaian pembayaran, layanan kredit, pemasaran, manajemen risiko dan pengendalian internal.

Dalam rangka membangun budaya belajar dan memfasilitasi proses belajar di perusahaan, BCA mengembangkan metode pembelajaran secara online $(E$ Learning). Menurut [1] E-Learning BCA merupakan 
"metode pembelajaran secara online melalui Learning Managemant System (LMS) dengan web intrabca yang memungkinkan pekerja untuk belajar dimanapun selama masih terkoneksi dengan web intrabca dengan waktu yang flexsibel. Materi yang ditawarkan melalui E-Lerning akan selalu dikembangkan sesuai dengan kebutuhan pengembangan karyawan, sehinga selanjutnya diharapkan E-Learning akan melengkapi metode pembelajaran BCA”.

Berdasarkan uraian di atas, perumusan masalah yang didapat dalam penelitian ini, yaitu: (1) Bagaimana penerapan E-Learning sebagai media pelatihan dan pengembangan pada karyawan BCA KC Tangerang; (2) Bagaimana kinerja karyawan BCA KCU Tangerang; (3) Bagaimana pengaruh penerapan E-Learning sebagai media pelatihan dan pengembangan terhadap kinerja pada karyawan BCA KCU Tangerang. Tujuan dari penelitian ini, sebagai berikut: (1) Mengetahui bagaimana penerapan e-learning sebagai media pelatihan dan pengembangan terhadap kinerja karyawan BCA KCU Tangerang; (2) Mengetahui bagaimana kinerja karyawan BCA KCU Tangerang; (3) Mengetahui bagaimana hubungan pengaruh penerapan e-learning sebagai media pelatihan dan pemgembangan terhadap kinerja karyawan BCA KCU Tangerang.

\section{LANDASAN TEORI}

\subsection{Pengertian E-Learning}

Sistem pembelajaran elektronik atau e-pembelajaran (Inggris: Electronic Learning disingkat E-Learning) merupakan cara baru dalam proses belajar mengajar. ELearning merupakan dasar dari konsekuensi logis dari perkembangan teknologi informasi dan komunikasi. Menggunakan e-learning, peserta ajar (learner) dapat berperan aktif dalam pencarian informasi maupun pengetahuan baru. Salah satu dari definisi dari e-learning diberikan oleh Gilbert dan Jones yaitu pengiriman materi pembelajaran melalui media elektronik seperti internet, intanetekstanet, satelit broadcast, audio/video tape, interactive TV, CD Room, dan computer based training (CBT) [12].

E-Learning adalah sistem pembelajaran yang memanfaatkan media elektronik sebagai alat untuk membantu kegiatan pembelajaran [3]. Implementasi penggunaan e-learning yang ada pada saat ini sangat bervariasi, namun semua itu didasarkan pada prinsip atau konsep bahwa $e$ - learning yang dimaksud sebagai upaya pendistribusian materi pembelajaran melalui media elektronik atau internet [12].

Menurut [9] bahwa terdapat tiga karakteristik penting dalam pembelajaran e-learning. Pertama, e-learning berkaitan dengan jaringan elektronik yang memungkinkan informasi dan instruksi disampaikan. Kedua, e-learning disampaikan pada learner mengggunakan komputer dengan teknologi internet. Ketiga, pada solusi pembelajaran yang melebihi pelatihan tradisional termasuk penyampaian informasi dan alat untuk meningkatkan kinerja.

\subsection{Pengertian Pelatihan dan Pengembangan}

Menurut [10] Pelatihan dan Pengembangan merupakan kegiatan yang bermaksud memperbaiki dan mengembangkan sikap, perilaku, keterampilan, dan pengetahuan para karyawan sesuai dengan keinginan perusahaan. Pelatihan dan pengembangan ditujukan untuk mempertahankan dan meningkatkan prestasi kerja para karyawan.

\subsection{Pengertian Kinerja Karyawan}

Menurut [11] kinerja adalah hasil atau tingkat keberhasilan seseorang atau keseluruhan selama periode tertentu didalam melaksanakan tugas dibandingkan dengan berbagai kemingkinan, seperti standar hasil kerja, target atau sasaran atau kriteria yang telah ditentukan terlebih dahulu dan telah disepakati bersama.

Menurut [6] bahwa: "kinerja adalah hasil kerja secara kualitas dan kuantitas yang dicapai oleh seorang pegawai dalam melaksanakan tugasnya sesuai dengan tanggung jawab yang diberikan kepadanya".

Menurut [7] kinerja karyawan adalah hasil proses pekerjaan tertentu secara terencana pada waktu dan tempat dari karyawan serta organisasi yang bersangkutan.

\section{METODOLOGI PENELITIAN}

\subsection{Tahapan Penelitian}

Proses penelitian ini terdiri dari lima tahap yaitu, penentuan identifikasi masalah, pengembangan kerangka teori, penentuan metodologi, analisis data dan pengambilan kesimpulan. Proses penelitian diawali penentuan topik peneltian dengan mengumpulkan informasi atas permasalahan yang diteliti yaitu informasi mengenai pengaruh e-learning sebagai media pelatihan dan pengembangan terhadap kinerja karyawan BCA KCU Tangerang.

Tahap selanjutnya ialah pengembangan kerangka teori dengan mengumpulkan bahan-bahan kepustakaan yang terkait dengan topik permasalahan penelitian. Selanjutnya, peneliti memilih metode penelitian. Penelitian yang di lakukan bersifat atau menggunakan metode deskriptif. Menurut [8], "Metode desktiptif adalah suatu metode dalam meneliti status, sekelompok manusia, suatu objek, suatu sistem pemikiran ataupun suatu kelas peristiwa pada masa sekarang".Teknik pengumpulan data melalui teknik survey dengan menyebarkan kuisioner. Penelitian Survey yaitu penelitian yang dilakukan dengan maksud mengetahui sesuatu secara keseluruhan dari wilayah/objek penelitian. Kesimpulan dari hasil penelitian tersebut berlaku umum (general) untuk seluruh wilayah yang menjadi sasaran [13]. Dalam penyebaran kuisoner dilakukan langsung dengan mendatangi para responden ke bank. Sebelumya, melakukan konfirmasi dengan pihak bank dan memberikan penjelasan 
mengenai tujuan penelitian dan meminta kesediaan responden untuk mengisi instrument penelitian.

Setelah mendapatkan data, kemudian data tersebut diolah dan dianalisi dengan menggunakan analisis kuantitatif. Menurut [2] penelitian kuantitatif memusatkan perhatian pada gejala-gejala yang mempunyai kharakteristik tertentu didalam kehidupan manusia yang dinamakan variabel, hakikat diantara variabel-variabel dianalisa dengan menggunakan teori yang objektif.

Pada tahap ini akhir hasil dari penelitian diolah untuk selanjutnya dianalisis dan ditarik kesimpulan.

\subsection{Instrumen Penelitian}

Instrumen yang digunakan dalam penelitian ini adalah instrumen kuesioner untuk variabel e-learning sebagai media pelatihan dan pengembangan (variable X) dan Kinerja Karyawan (variable Y). Untuk mengetahui bagaimana pengaruh pelatihan dan pengembangan sumber daya manusia terhadap kinerja karyawan, dilakukan dengan menggunakan skala likert. Menurut [4] skala Likert yaitu skala yang digunakan untuk mengukur sikap, pendapat, persepsi seseorang atau sekelompok orang tentang fenomena sosial. Jawaban setiap item instrument yang menggunakan skala likert mempunyai gradasi dari segi sangat positif sampai sangat negatif, yang berupa kata-kata yang antara lain dapat di lihat pada tabel berikut:

Tabel 1. Skala Likert

\begin{tabular}{|c|c|c|c|c|}
\hline $\begin{array}{c}\text { Sangat } \\
\text { Setuju }\end{array}$ & Setuju & $\begin{array}{c}\text { Ragu- } \\
\text { ragu }\end{array}$ & $\begin{array}{c}\text { Tidak } \\
\text { Setuju }\end{array}$ & $\begin{array}{c}\text { Sangat } \\
\text { Tidak } \\
\text { Setuju }\end{array}$ \\
\hline$(\mathrm{SS})$ & $(\mathrm{S})$ & $(\mathrm{R})$ & $(\mathrm{TS})$ & $(\mathrm{STS})$ \\
\hline 5 & 4 & 3 & 2 & 1 \\
\hline
\end{tabular}

3.3. Metode Pengumpulan Data, Populasi dan Sample Penelitian

\subsubsection{Metode Pengumpuan Data}

Untuk memperoleh hasil penelitian diperlukan data dan informasi yang dapat mendukung penelitian ini. Peneliti melakukan langkah-langkah pengumpulan data, sebagai berikut: (1) Observasi; (2) Wawancara; (3) Kuisoner; dan (4) Kepustakaan.

\subsubsection{Populasi dan Sampel Penelitian}

Populasi dalam penelitian ini adalah karyawan tetap BCA KCU Tangerang yang dapat mengakses sistem $e$ learning dengan jumlah karyawan sebanyak 45 orang karyawan. Sedangkan teknik penarikan sampel dengan menggunakan metode sensus/ sampling jenuh, yakni penentuan sampel dengan mengambil keseluruhan jumlah populasi yang ada, sehingga dalam penelitian ini jumlah sampel ditentukan sebanyak 45 orang karyawan yang memenuhi persyaratan tersebut. Mengacu pada 45 orang yang memenuhi syarat maka kuesioner yang disebar adalah sejumlah 45 kuesioner.
Dari hasil penelitian, kuesioner yang kembali sebanyak 43 kuesioner, 2 kuesioner kosong dan ada 3 kuesioner yang tidak diisi secara lengkap. Oleh karena itu jumlah kuesioner yang dapat digunakan sejumlah 40 kuesioner.

\subsection{Metode Analisis Data}

Setelah seluruh data diperoleh, maka diperlukan suatu alat untuk menganalisa guna menguji data-data yang tersedia. Dalam penelitian ini analisa data menggunakan metode statistik, analisa regresi dan korelasi. Agar lebih memperjelas hubungan antar variabel. Untuk menganalisis data ke dalam regresi sederhana tersebut digunakan software SPSS.

\section{HASIL DAN PEMBAHASAN}

\subsection{Gambaran Umum Responden}

Tujuan dari analisis deskriptif dalam penelitian ini yaitu untuk menganalisis data yang berhubungan dengan identitas responden yang meliputi jenis kelamin, usia, lama bekerja.

4.1.1 Jenis Kelamin

Dalam klasifikasi ini jenis kelamin dapat dikelompokkan menjadi dua kelompok, seperti yang tercantum pada tabel berikut ini :

Tabel 2. Karakteristik Responden Berdasarkan Jenis Kelamin

\begin{tabular}{|c|c|c|}
\hline $\begin{array}{c}\text { Jenis } \\
\text { Kelamin }\end{array}$ & Responden & Persentase \% \\
\hline Laki-laki & 13 & $32 \%$ \\
\hline Perempuan & 27 & $67 \%$ \\
\hline Total & 40 & $100 \%$ \\
\hline
\end{tabular}

Tabel 2 menunjukkan mayoritas jenis kelamin responden adalah wanita yang berjumlah 27 dengan persentase $32 \%$, sedangkan sisanya adalah Pria yang berjumlah 13 orang atau sebesar $32 \%$. Hal ini menunjukkan bahwa BCA KCU Tangerang lebih banyak mempekerjakan karyawan Wanita.

\subsubsection{Usia}

Dalam klasifikasi ini usia di BCA KCU Tangerang dikelompokkan menjadi tiga kelompok, seperti yang tercantum pada tabel berikut ini:

Tabel 3.Karakteristik Responden Berdasarkan Usia

\begin{tabular}{|c|c|c|}
\hline Usia & Responden & Persentase \% \\
\hline $21-30$ & 20 & $50 \%$ \\
\hline $31-40$ & 16 & $40 \%$ \\
\hline$>40$ & 4 & $10 \%$ \\
\hline Total & 40 & $100 \%$ \\
\hline
\end{tabular}

Tabel 3 menunjukkan mayoritas usia responden yang diteliti adalah 21-30 tahun sebanyak 20 orang atau sebesar $50 \%$, pada usia 31-40 tahun sebanyak 16 orang atau sebesar 
$40 \%$ dan pada usia $>40$ sebanyak 4 orang atau sebesar $13 \%$. Hal ini menunjukkan bahwa BCA KCU Tangerang lebih banyak mempekerjakan karyawan berusia muda karena dianggap produktif.

\subsubsection{Lama Kerja}

Dalam klasifikasi ini, lama bekerja di BCA KCU Tangerang dikelompokkan menjadi tiga kelompok, seperti yang tercantum pada tabel berikut ini :

Tabel 4. Karakteristik Responden Berdasarkan Lama Kerja

\begin{tabular}{|c|c|c|}
\hline $\begin{array}{c}\text { Lama } \\
\text { Kerja }\end{array}$ & Responden & $\begin{array}{c}\text { Persentase } \\
\text { \% }\end{array}$ \\
\hline < 4 Tahun & 6 & $15 \%$ \\
\hline 5-7 Tahun & 8 & $20 \%$ \\
\hline$>8$ Tahun & 26 & $65 \%$ \\
\hline Total & 40 & $100 \%$ \\
\hline
\end{tabular}

Berdasarkan data tersebut responden didominasi oleh karyawan dengan lama bekerja 5 tahun -7 tahun sebanyak $15 \%$ atau sebanyak 6 orang. Untuk karyawan dengan lama bekerja < 4 tahun sebanyak $20 \%$ atau sebanyak 8 orang.Sedangkan karyawan dengan lama bekerja $>8$ tahun sebanyak $65 \%$ atau sebanyak 26 orang. Dapat disimpulkan berarti responden dengan lama bekerja > 8 tahun lebih banyak jumlahnya.

4.2 Analisis Penerapan e-learning sebagai media pelatihan dan pengembangan karyawan BCA KCU Tangerang

Untuk lebih memudahkan dalam menganalisis, maka tanggapan responden terhadap penerapan e-learning disajikan dalam bentuk tabel secara keseluruhan sebagai berikut :

Tabel 5. Analisa Tanggapan Responden Mengenai Penerapan E-Learning sebagai Media Pelatihan dan Pengembangan Karyawan BCA KCU Tangerang

\begin{tabular}{|c|l|c|c|c|}
\hline No & \multicolumn{1}{|c|}{ Pernyataan } & Jml & $\begin{array}{c}\text { Rata } \\
\text { Rata }\end{array}$ & Ket \\
\hline 1 & $\begin{array}{l}\text { Navigasi pada sistem } \\
\text { memudahkan learner dalam } \\
\text { melakukan pembelajaran. } \\
\text { Misalnya tombol melanjutkan } \\
\text { halaman, tombol kembali ke } \\
\text { halaman sebelumnya, tombol } \\
\text { kembali ke menu utama, tombol } \\
\text { keluar dll }\end{array}$ & 153 & 3.82 & Baik \\
\hline 2 & $\begin{array}{l}\text { Sistem dalam } e \text {-learning } \\
\text { dikemas dengan atraktif dan } \\
\text { menarik minat learner untuk } \\
\text { belajar. }\end{array}$ & 172 & 4.3 & $\begin{array}{c}\text { Sangat } \\
\text { Baik }\end{array}$ \\
\hline
\end{tabular}

\begin{tabular}{|c|c|c|c|c|}
\hline No & Pernyataan & Jml & $\begin{array}{l}\text { Rata } \\
\text { Rata }\end{array}$ & Ket \\
\hline 3 & $\begin{array}{l}\text { Terdapat kejelasan teks dan } \\
\text { visual (grafis). Dalam setiap } \\
\text { modul, ukuran font ideal, } \\
\text { memiliki space yang ideal, teks } \\
\text { terbaca jelas dengan background } \\
\text { yang ideal }\end{array}$ & 159 & 3.97 & Baik \\
\hline 4 & $\begin{array}{l}\text { Materi diatur dengan urutan } \\
\text { yang baik, dikemas dalam } \\
\text { bentuk modul-modul singkat } \\
\text { padat untuk fleksibelitas } \\
\text { pembelajaran }\end{array}$ & 159 & 3.97 & Baik \\
\hline 5 & $\begin{array}{l}\text { E-Learning menyediakan } \\
\text { aktivitas latihan yang efektif. } \\
\text { Untuk proses pelatihan tidak } \\
\text { membutuhkan biaya transport } \\
\text { dan kelas. }\end{array}$ & 171 & 4.27 & $\begin{array}{c}\text { Sangat } \\
\text { Baik }\end{array}$ \\
\hline 6 & $\begin{array}{l}\text { Materi yang disampaikan dalam } \\
\text { sistem akurat berguna bagi } \\
\text { kelancaran pekerjaan di unit } \\
\text { kerja anda }\end{array}$ & 182 & 4.55 & $\begin{array}{c}\text { Sangat } \\
\text { Baik }\end{array}$ \\
\hline 7 & $\begin{array}{l}\text { E-Learning dapat mudah } \\
\text { diakses oleh seluruh karyawan, } \\
\text { kapan saja sehingga tidak } \\
\text { menggangu jam kerja }\end{array}$ & 180 & 4.5 & $\begin{array}{c}\text { Sangat } \\
\text { Baik }\end{array}$ \\
\hline 8 & $\begin{array}{l}\text { Materi dalam e-learning } \\
\text { bervariasi dan selalu update oleh } \\
\text { perusahaan mengikuti kebutuhan } \\
\text { pengetahuan bagi karyawan. }\end{array}$ & 167 & 4.17 & $\begin{array}{c}\text { Sangat } \\
\text { Baik }\end{array}$ \\
\hline 9 & $\begin{array}{l}\text { E-Learning membangun } \\
\text { Learning Culture yang baik } \\
\text { dalam berorganisasi di unit anda } \\
\text { bekerja }\end{array}$ & 153 & 3.82 & Baik \\
\hline 10 & $\begin{array}{l}\text { E-Learning meningkatkan } \\
\text { hardskil yang baik untuk } \\
\text { karyawan }\end{array}$ & 157 & 3.82 & Baik \\
\hline & \multicolumn{2}{|c|}{ Jumlah } & 41.2 & \\
\hline & \multicolumn{2}{|c|}{ Rata-Rata } & 4.12 & Baik \\
\hline
\end{tabular}

Jadi, dilihat dari Tabel 5 bahwa e-learning sebagai media pelatihan dan pengembagan yang diterapkan di BCA KCU Tangerang dapat dikatakan baik, karena nilai rata-rata dari keseluruhan pernyataan adalah sebesar 4.12 berada pada interval 3,39 $-4,20=$ Baik.

\subsection{Analisis Kinerja Karyawan BCA KCU Tangerang}

Tabel 6. Analisa Tanggapan Responden Mengenai Kinerja Karyawan BCA KCU Tangerang

\begin{tabular}{|c|l|c|c|c|}
\hline No & \multicolumn{1}{|c|}{ Pernyataan } & Jml & $\begin{array}{c}\text { Rata } \\
\mathbf{2}\end{array}$ & Ket \\
\hline 1 & $\begin{array}{l}\text { Saya dapat melaksanakan } \\
\text { pekerjaan sesuai waktu yang } \\
\text { telah ditentukan }\end{array}$ & 165 & 4.13 & $\begin{array}{c}\text { Sangat } \\
\text { Baik }\end{array}$ \\
\hline 2 & $\begin{array}{l}\text { Saya mempunyai } \\
\text { pengetahuan yang baik di } \\
\text { bidang pekerjaan }\end{array}$ & 172 & 4.3 & $\begin{array}{c}\text { Sangat } \\
\text { Baik }\end{array}$ \\
\hline
\end{tabular}


Jurnal SISFOKOM, Volume 07, Nomor 01, Maret 2018

\begin{tabular}{|c|c|c|c|c|}
\hline No & Pernyataan & $\mathbf{J m l}$ & $\begin{array}{c}\text { Rata } \\
2\end{array}$ & Ket \\
\hline 3 & $\begin{array}{l}\text { Saya bekerja dengan } \\
\text { menggunakan standar } \\
\text { operasi operasioal (SOP) } \\
\text { dari perusahaan }\end{array}$ & 164 & 4.1 & $\begin{array}{c}\text { Sangat } \\
\text { Baik }\end{array}$ \\
\hline 4 & $\begin{array}{l}\text { Saya mampu menganalisis } \\
\text { data/informasi yang telah } \\
\text { tersedia diperusahaan }\end{array}$ & 178 & 4.45 & $\begin{array}{c}\text { Sangat } \\
\text { Baik }\end{array}$ \\
\hline 5 & $\begin{array}{l}\text { Saya tidak pernah gagal } \\
\text { dalam mengunakan mesin/ } \\
\text { peralatan yang disediakan } \\
\text { perusahaan }\end{array}$ & 174 & 4.35 & $\begin{array}{c}\text { Sangat } \\
\text { Baik }\end{array}$ \\
\hline 6 & $\begin{array}{l}\text { Saya berusaha untuk dapat } \\
\text { mencapai target yang } \\
\text { perusahaan tetapkan }\end{array}$ & 154 & 3.85 & Baik \\
\hline 7 & $\begin{array}{l}\text { Saya dapat bekerjasama } \\
\text { dengan semua karyawan } \\
\text { yang berada di perusahaan }\end{array}$ & 170 & 4.25 & $\begin{array}{c}\text { Sangat } \\
\text { Baik }\end{array}$ \\
\hline 8 & $\begin{array}{l}\text { Saya dapat menciptakan } \\
\text { suasana kerja yang baik di } \\
\text { perusahaan }\end{array}$ & 179 & 4.48 & $\begin{array}{c}\text { Sangat } \\
\text { Baik }\end{array}$ \\
\hline 9 & $\begin{array}{l}\text { Saya selalu berusaha } \\
\text { melakukan tugas pekerjaan } \\
\text { yang sudah menjadi } \\
\text { tanggung jawab saya }\end{array}$ & 171 & 4.28 & $\begin{array}{c}\text { Sangat } \\
\text { Baik }\end{array}$ \\
\hline 10 & $\begin{array}{l}\text { Saya bersedia dan } \\
\text { bertanggung jawab } \\
\text { menerima tugas baru yang } \\
\text { di berikan atasan }\end{array}$ & 151 & 3.78 & Baik \\
\hline & & umlah & 42 & \\
\hline & \multicolumn{2}{|c|}{ Rata-Rata } & 4.2 & $\begin{array}{c}\text { Sangat } \\
\text { Baik }\end{array}$ \\
\hline
\end{tabular}

Jadi, dilihat dari Tabel 6 bahwa kinerja karyawan BCA KCU Tangerang dapat dikatakan sangat baik, karena nilai rata-rata dari keseluruhan pernyataan adalah sebesar 4,2 berada pada interval 4,20 - 5,00 = Sangat Baik.

\subsection{Uji Validitas}

Dengan menggunakan rumus korelasi product moment diketahui jumlah responden sebanyak 40 dan jumlah butir pernyataan sebanyak 10 dengan tingkat signifikansi $5 \%(\mathrm{n}=40, \alpha=0,05)$ maka $\mathrm{r}$ tabel $=0,312$, disimpulan terdapat 10 butir pernyataan yang dinyatakan valid dengan rincian sebagai berikut:

Tabel 7. Uji Validitas Variabel e-learning

\begin{tabular}{|c|c|c|c|}
\hline $\begin{array}{c}\text { Nomor } \\
\text { Pernyataan }\end{array}$ & R-Hitung & R-Tabel & Keterangan \\
\hline 1 & 0.597 & 0.312 & Valid \\
\hline 2 & 0.389 & 0.312 & Valid \\
\hline 3 & 0.364 & 0.312 & Valid \\
\hline 4 & 0.381 & 0.312 & Valid \\
\hline 5 & 0.489 & 0.312 & Valid \\
\hline 6 & 0.332 & 0.312 & Valid \\
\hline 7 & 0.627 & 0.312 & Valid \\
\hline 8 & 0.386 & 0.312 & Valid \\
\hline 9 & 0.587 & 0.312 & Valid \\
\hline 10 & 0.694 & 0.312 & Valid \\
\hline
\end{tabular}

Tabel 8. Uji Validitas Variabel Kinerja

\begin{tabular}{|c|c|c|c|}
\hline $\begin{array}{c}\text { Nomor } \\
\text { Pernyataan }\end{array}$ & $\begin{array}{c}\text { R- } \\
\text { Hitung }\end{array}$ & $\begin{array}{c}\text { R- } \\
\text { Tabel }\end{array}$ & Keterangan \\
\hline 1 & 0.424 & 0.312 & Valid \\
\hline 2 & 0.549 & 0.312 & Valid \\
\hline 3 & 0.378 & 0.312 & Valid \\
\hline 4 & 0.412 & 0.312 & Valid \\
\hline 5 & 0.529 & 0.312 & Valid \\
\hline 6 & 0.784 & 0.312 & Valid \\
\hline 7 & 0.621 & 0.312 & Valid \\
\hline 8 & 0.604 & 0.312 & Valid \\
\hline 9 & 0.398 & 0.312 & Valid \\
\hline 10 & 0.484 & 0.312 & Valid \\
\hline
\end{tabular}

4.5 Uji Reabilitas

Uji reliabilitas dimaksudkan untuk mengukur suatu kuesioner yang merupakan indikator dari variabel. Reabilitas diukur dengan uji statistik cronbach's alpha $(\alpha)$. Suatu variabel dikatakan reliabel jika memberikan nilai cronbach' alpha $>0,60$ atau r-tabel.

Tabel 9. Uji Reabilitas Instrumen Penelitian

\begin{tabular}{|c|c|c|c|c|}
\hline Variabel & $\begin{array}{c}\text { Cronbac } \\
\text { h'alpha }\end{array}$ & Kriteria & $\begin{array}{c}\text { R- } \\
\text { Tabel }\end{array}$ & Ket \\
\hline $\begin{array}{c}\text { E- } \\
\text { Learning }\end{array}$ & 0.629 & 0.6 & 0.321 & Realibel \\
\hline Kinerja & 0.698 & 0.6 & 0.321 & Realibel \\
\hline
\end{tabular}

4.6 Uji Normalitas

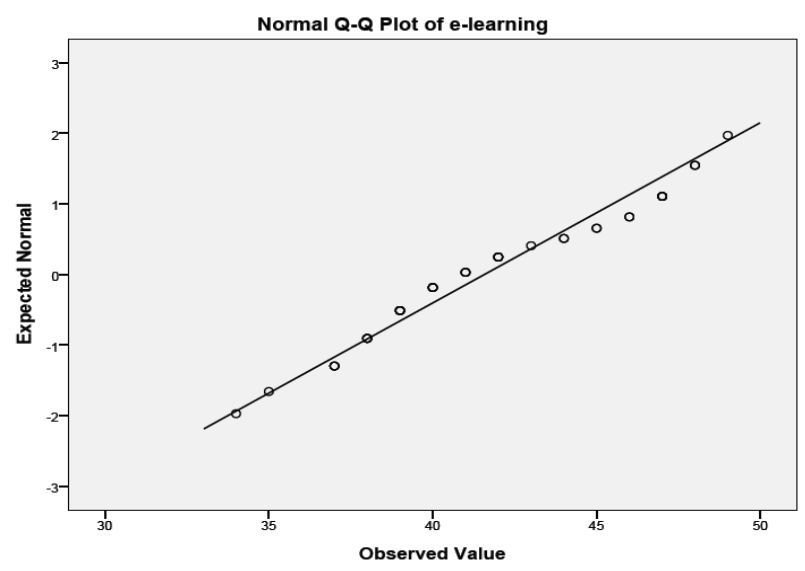

Gambar 1. Grafik P-Plot Variabel X

Berdasarkan gambar grafik p-plot pada gambar 1 bahwa data menyebar di sekitar garis diagonal dan mengikuti arah garis diagonal, dengan demikian dapat disimpulkan bahwa data variabel e-learning (X) berdistribusi normal. 


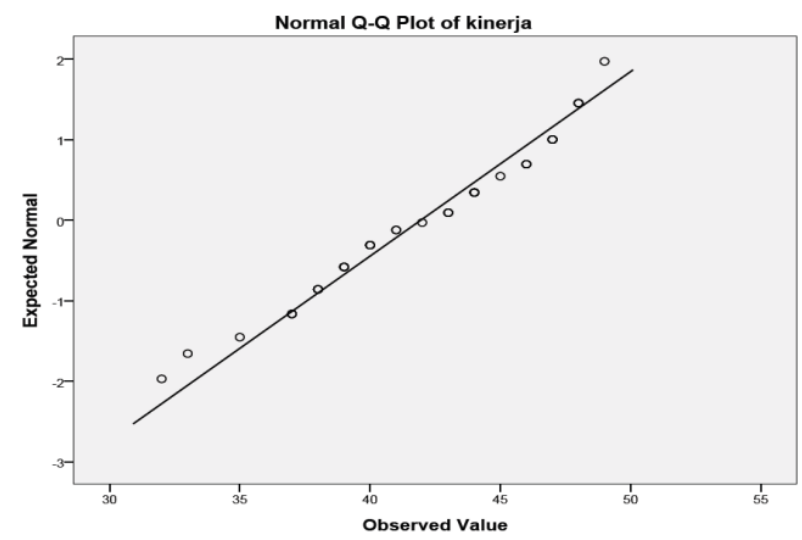

Gambar 2. Grafik P-Plot Variabel Y

Berdasarkan gambar grafik p-plot pada gambar 2 bahwa data menyebar di sekitar garis diagonal dan mengikuti arah garis diagonal, dengan demikian dapat disimpulkan bahwa data variabel kinerja (y) berdistribusi normal.

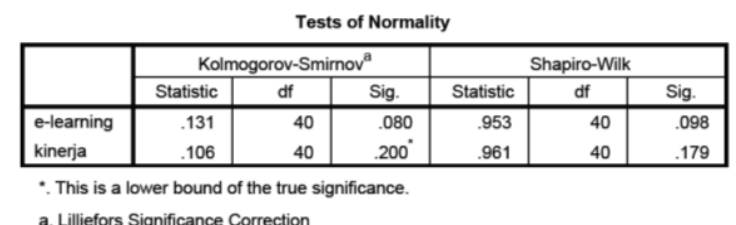

Gambar 3. Snapshot Tabel Hasil Uji Normalitas

Hasil pengujian menunjukkan bahwa tingkat signifikansi variabel e-learning $(\mathrm{X})=0.98$ dan tingkat signifikasi variable kinerja $(\mathrm{Y})=0.179$ yang lebih besar dari 0,05 sehingga dapat disimpulkan bahwa model penelitian memiliki distribusi data normal.

\subsection{Analisa Regresi Sederhana}

Untuk mengetahui pengaruh e-learning (X) terhadap kinerja karyawan (Y), maka digunakan analisis regresi sederhana sbb:

\begin{tabular}{|c|c|c|c|c|c|c|}
\hline \multicolumn{7}{|c|}{ Coefficients $^{a}$} \\
\hline \multirow{2}{*}{\multicolumn{2}{|c|}{ Model }} & \multicolumn{2}{|c|}{ Unstandardized Coefficients } & \multirow{2}{*}{$\begin{array}{c}\begin{array}{c}\text { Standardized } \\
\text { Coefficients }\end{array} \\
\text { Beta }\end{array}$} & \multirow[b]{2}{*}{$t$} & \multirow[b]{2}{*}{ Sig. } \\
\hline & & $B$ & Std. Error & & & \\
\hline 1 & (Constant) & 23.022 & 6.898 & & 3.337 & .002 \\
\hline & e-learning & .455 & .165 & .408 & 2.756 & .009 \\
\hline
\end{tabular}

Gambar 4. Snapshot Tabel Hasil Regresi Linier Sederhana

Berdasarkan tabel diatas didapat persamaan regresi sebagai berikut:

$$
\mathbf{Y}=\mathbf{2 3 . 0 2 2}+\mathbf{0 . 4 5 5 X}
$$

Maka fungsi persamaan regresi $a+b=23.022+0,455$ hal ini menunjukkan sebagai berikut:

1. Bila perusahaan tidak menerapkan e-learning sebagai media pelatihan dan pengembangan atau $\mathrm{b}=0$ maka kinerja karyawan 23.022.
2. Jika perusahaan menerapkan e-learning sebagai media pelatihan dan pengembangan dilaksanakan dengan lebih baik, maka kinerja karyawan akan meningkat sebesar 0.455 .

4.8 Analisa Koefisien Korelasi

Analisis ini digunakan untuk mengetahui kuat atau lemahnya hubungan pada. Analisis ini menggunakan korelasi product moment dengan rumus sebagai berikut:

$$
\begin{aligned}
& r=\frac{\mathrm{n} \cdot \sum \mathrm{xy}-\sum \mathrm{x} \cdot \sum \mathrm{y}}{\sqrt{\mathrm{n} \cdot \sum \mathrm{x}^{2}-\left(\sum \mathrm{x}\right)^{2}} \cdot \sqrt{\mathrm{n} \cdot \sum \mathrm{y}^{2}-\left(\sum \mathrm{y}\right)^{2}}} \\
& r=\frac{40 \cdot(70035)-(1663) \cdot(1678)}{\sqrt{40 \cdot(69737)-(1663)^{2}} \cdot \sqrt{40 \cdot(71136)-(1678)^{2}}} \\
& r=0.408 \\
& r=0.40
\end{aligned}
$$

Dari hasil perhitungan diatas, dapat diperoleh nilai koefisien korelasi sebesar 0,40 yang berarti masuk dalam katageri cukup berpengaruh dimana $r>0$, artinya telah terjadi hubungan linear positif yaitu makin besar nilai variable $\mathrm{x}$ (e-learning) maka makin besar pula nilai variable y (kinerja) atau makin kecilnya nilai variable x (e-learning) maka makin kecil pula nilai variable y (kinerja).

\subsection{Analisa Koefisien Determinasi}

Model Summary ${ }^{\mathrm{b}}$

\begin{tabular}{|l|c|c|c|c|}
\hline Model & $\mathrm{R}$ & $\mathrm{R}$ Square & $\begin{array}{c}\text { Adjusted R } \\
\text { Square }\end{array}$ & $\begin{array}{c}\text { Std. Error of the } \\
\text { Estimate }\end{array}$ \\
\hline 1 & $.408^{\mathrm{a}}$ & .167 & .145 & 4.039 \\
\hline
\end{tabular}
a. Predictors: (Constant), e-learning
b. Dependent Variable: kinerja

Gambar 5. Snapshot Tabel Hasil Koefisien Determinasi $\left(\mathrm{r}^{2}\right)$

$$
\begin{aligned}
& \mathrm{KD}=\mathrm{r}^{2} \times 100 \% \\
& \mathrm{KD}=0,40^{2} \times 100 \% \\
& \mathrm{KD}=0,40^{2} \times 100 \% \\
& \mathrm{KD}=16 \%
\end{aligned}
$$

Hal ini menunjukkan besarnya pengaruh pendidikan dan pelatihan terhadap kinerja karyawan adalah sebesar $16 \%$, sedangkan sisanya $84 \%$ dipengaruhi oleh faktor lain yang tidak di teliti.

\subsection{Uji Signifikasi (Uji t)}

Untuk mengetahui diterima atau ditolaknya suatu hipotesis, maka $\mathrm{t}$ hitung dibandingkan dengan $\mathrm{t}$ tabel. Kriteria untuk menentukan apakah Ho ditolak atau diterima adalah sebagai berikut :

1. Jika $\mathrm{t}$ hitung $>\mathrm{t}$ tabel maka Ha diterima dan Ho ditolak

2. Jika $\mathrm{t}$ hitung $<\mathrm{t}$ tabel maka $\mathrm{Ha}$ ditolak dan $\mathrm{Ho}$ diterima.

3. Dalam menentukan diterima atau ditolaknya hipotesis maka harus dicari nilai dari t tabel dengan 
menentukan degree of freedom (df) atau derajat kebebasan.Dimana derajat kebebasan (df) adalah :

$\mathrm{Df}=\mathrm{n}-2$

Df $=40-2$

Df $=38$

4. Tingkat kekeliruan (a) yang digunakan sebesar $5 \%$. Untuk mendapatkan nilai t hitung sebagai berikut :

\begin{tabular}{|c|c|c|c|c|c|c|}
\hline \multicolumn{7}{|c|}{ Coefficients $^{\mathrm{a}}$} \\
\hline \multirow[b]{2}{*}{ Model } & & \multicolumn{2}{|c|}{ Unstandardized Coefficients } & \multirow{2}{*}{$\begin{array}{c}\begin{array}{c}\text { Standardized } \\
\text { Coefficients }\end{array} \\
\text { Beta }\end{array}$} & \multirow[b]{2}{*}{$t$} & \multirow[b]{2}{*}{ Sig. } \\
\hline & & $B$ & Std. Error & & & \\
\hline \multirow[t]{2}{*}{1} & (Constant) & 23.022 & 6.898 & & 3.337 & .002 \\
\hline & e-learning & .455 & .165 & .408 & 2.756 & .009 \\
\hline
\end{tabular}

a. Dependent Variable: kineria

\section{Gambar 6. SnapshotTabel Hasil Uji T}

Dari perhitungan statistik uji $\mathrm{t}$ diatas ternyata $\mathrm{t}$ hitung $=2,756$ lebih besar dari $\mathrm{t}$ tabel $=1,686$ maka Ha diterima dan $\mathrm{H}_{0}$ ditolak. Ini berarti terdapat pengaruh positif antara penerapan e-learning sebagai media pelatihan dan pengembangan terhadap kinerja karyawan. Berdasarkan gambar di atas t hitung sebesar 2,756 berada pada daerah penolakan $\mathrm{H}_{0}$ sehingga dapat disimpulkan bahwa variabel penerapan e-learning sebagai media pelatihan dan penembangan berpengaruh terhadap kinerja karyawan.

\section{PENUTUP}

Berdasarkan hasil penelitian dan pembahasan pengaruh e-learning sebagai media pelatihan dan pengembangan terhadap kinerja karyawan dengan melalui penyebaran kuesioner kepada nasabah karyawan BCA KCU Tangerang, maka didapat kesimpulan sebagai berikut:

1. Hasil secara keseluruhan yang didapatkan bahwa penerapan e-learning sebagai media pelatihan dan pengembangan pada karyawan BCA KCU Tangerang sudah berjalan dengan baik. Hal tersebut terbukti dari hasil pengolahan data kuesioner menunjukan bahwa yang menjadi dasar pertimbangan mengenai penerapan sistem e-learning semuanya menghasilkan kriteria baik. Ini terbukti dari hasil perhitungan analisis pernyataan responden mengenai e-learning, jawaban responden terhadap setiap pernyataan yang diajukan secara keseluruhan menghasilkan kriteria sangat baik dengan ratarata 4,12 dan ini berarti kualifikasi yang menjadi dasar penerapan e-learning sebagai media pelatihan dan pengembangan sudah sangat baik sesuai dengan nilainya yang berada pada interval 3,40 - 4,19. Jadi menurut responden penerapan e-learning sebagai media pelatihan dan pengembngan pada karyawan BCA KCU Tangerang dilaksanakan dengan baik.

2. Berdasarkan hasil secara keseluruhan terhadap kinerja karyawan BCA KCU Tangerang sudah berada pada kriteria sangat baik. Ini terlihat dari jawaban responden secara keseluruhan terhadap setiap peryataan yang diajukan dengan rata-rata 4,20 yang berada pada interval 4,20 - 5,00. Ini berarti faktor-faktor yang berperan terhadap hasil kinerja karyawan sudah sangat baik.

3. a. Hasil pengujian menunjukkan bahwa variabel elearning sebagai media

pelatihan dan pengembangan berpengaruh positif terhadap kinerja karyawan Dengan nilai t hitung $>\mathrm{t}$ tabel, $(2,756>1,686)$ dan Analisis Koefisien Korelasi yang dihitung $r=0,4$ berarti bahwa terdapat hubungan yang cukup baik dan searah antara e-learning (X) dengan kinerja (Y).

b. Hasil pengujian menunjukkan bahwa seperti diketahui $16 \%$ kinerja karyawan dapat dijelaskan oleh variabel e-learning, artinya 84\% dipengaruhi oleh variabel lain, yang tidak dalam cakupan penelitian.

\section{DAFTAR PUSTAKA}

[1] BCA. 2009. Surat Keputusan No. 010/SK/DIR/2009.

[2] Darmawan, Deni. 2013. Metode Penelitian Kuantitatif. Jakarta: Rosda, pp.130

[3] Daryanto. 2010. Media Pembelajaran Peranannya Sangat Penting dalam Mencapai Tujuan Pembelajaran. Yogyakarta: Gava Media, pp.168.

[4] Hasan, Iqbal. 2002. Metodelogi Penelitian dan Aplikasinya. Jakarta: Ghallia Indonesia.

[5] Kosasi, Sandy. 2015. Perancangan E-Learning Untuk meningkatkan Motivasi Belajar Guru Dan Siswa. Bali: Jurnal Perancangan E-learning Untuk Meningkatkan Motivasi Belajar Guru dan Siswa, ISSN 2087-2658, pp.82.

[6] Mangkunegara, Prabu, Anwar, AA. 2011. Sumber Daya Manusia Perusahaan. Bandung: Cetakan Kesembilan, PT. Remaja Rosdakarya. pp.67.

[7] Mangkuprawira, Safri. 2007. Manajemen Sumber Daya Manusia. Bogor: Cetakan pertama, Ghalia Indonesia Miles, Matthew \& Huberman, A. Michael. 1992. Analisis Data Kualitatif: Buku Sumber Tantang Metode-Metode Baru. Jakarta:Universitas Indonesia Press, pp.153.

[8] Nazir, Moh. Ph.D. 2014. Metode Penelitian. Bogor: Ghalia Indonesia.

[9] Noe, Raymond A. 2010. Employe Training and Development Fifth Edition. New York: McGraw Hill, pp.55.

[10] Rachmawati, Kusdiyah, Ike, Hj. 2008. Manajemen Sumber Daya Manusia. Yogyakarya: Penerbit C.V Andi Offset, pp.110.

[11] Sinambela, Poltak, Lijan. 2012. Kinerja Pegawai. Yogyakarta: Geraha Ilmu, pp.6.

[12] Surjono, H. D. 2011. Membangun Course E-Learning Berbasis Moodle. Yogyakarta: UNY Press, pp.1-3. 
[13] Syatori, Toto, Nasehudin \& Gozali, Nanang. 2012. Metode Penelitian Kuantitatif. Bandung: Pustaka Sedia.

\section{BIODATA PENULIS}

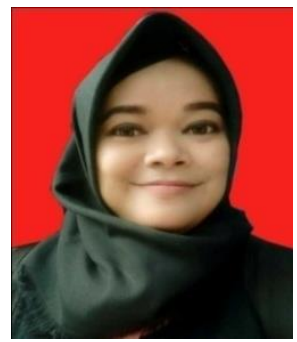

Indah Permatasari. Lahir di Jakarta, 03 Januari 1988. Lulus Sarjana (S1) Tahun 2017, Program Studi Sistem Informasi dari STMIK Nusa Mandiri dan Lulus Diploma 3 (Tiga), Tahun 2010, Program Studi Manajemen Informatika dari AMIK BSI Tangerang.

Riwayat pekerjaan: PT. Multitech Label Indonesia sebagai staf administrasi periode Tahun 2005-2007, PT. Krakatau Putra sebagai staf marketing periode Tahun 2007-2011, CV. Holi Cipta Selaras Sebagai Suvervisor Marketing Periode Tahun 2011-2013 dan PT. Bank Central Asia (PT. Dana Putra Investama) sebagai Staf Pengembang Bisnis Cabang per Tahun 2013Sekarang).

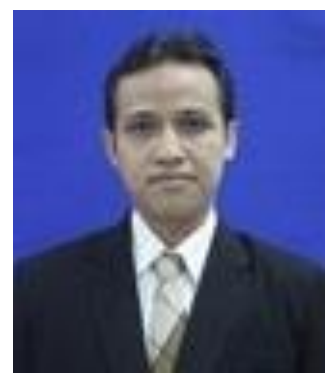

Hardiyan. Lahir di Tangerang, 13 November 1979. Lulus Strata 2 (S2) Tahun 2010 dari STMIK Nusa Mandiri Jakarta dan Sarjana (S1) dari STMIK Jakarta (STI\&K) Tahun 2004. Menjadi Staf Komputer Tahun 2006 di PT. Gramedia Asri Media, Staf IT Tahun 2007 di PT Inwha Indonesia dan Menjadi Dosen AMIK BSI Tangerang dari Tahun 2008Sekarang. Tulisan Paper jurnal yang sudah dipublikasikan, antara lain: Jurnal Paradigma Vol XIII No.1 Maret 2011, ISSN 1410-5963, dengan judul: "Fedora 14 dengan Virtual Sebagai Pembelajaran Linux Fundamental untuk Mahasiswa AMIK BSI Tangerang”, Jurnal Paradigma Vol. XV No.1 Maret 2013, ISSN 1410-5963, dengan judul: "Penilaian Efesiensi Relatif Paket Internet HotRod 3G+ Bagi Pelanggan XL", Jurnal Techno Nusa Mandiri Vol.XIII No.2 September 2016, ISSN: 1978-2136, dengan judul: "Decision Support System (DSS) dalam Pengangkatan Pelatih Pencak Silat Gerak Saka dengan Metode AHP" dan Jurnal Techno Nusa Mandiri Vol.XIV No.1 Maret 2017, ISSN: 19782136, dengan Judul: "Penerapan Model Waterfall Pada Program Aplikasi Pengolahan Nilai Siswa Online Pada SMP Islam Abaabiyl Tangerang”. 